\title{
INFLUENCE OF POLAR SOLVENTS ON THE ENHANCEMENT OF LIGHT-ENDS IN HEAVY CRUDE OIL DISTILLATION
}

\author{
O. R. Momoh ${ }^{1,}{ }^{*}$ E. B. Kolade ${ }^{2}$, C. S. Ajinomoh ${ }^{3}$, S. Bilal ${ }^{4}$, M. S. Galadima ${ }^{5}$ and M. I. Uzochukwu ${ }^{6}$

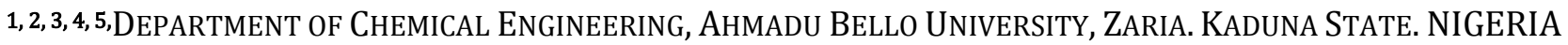

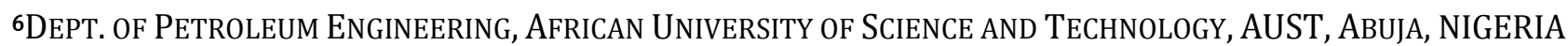 \\ E-mail addresses:10muyar2002@yahoo.com,2koladeee@gmail.com,3collinajinomo@yahoo.com, \\ 4 bsabiu@abu.edu.ng, 5 msgaladima@yahoo.com,6maryannanigbogu@yahoo.com
}

\begin{abstract}
Crude oil 'micelle' can be dispersed into fuels, oil and resin/asphalthene components using some hydrocarbon solvents. This can be adapted towards influencing/enhancing its product slates during the processing of crude oils. This research was carried out to investigate the effect of polar solvents (ethanol and acetone) in the enhancement of the light-ends in the True Boiling Point (TBP) distillation of Venezuela heavy crude oil. The oil was procured from Kaduna Refining and Petrochemical Company, Nigeria Ltd, Kaduna, Nigeria. Different concentrations of ethanol with crude oil blends were prepared using 2.5 wt.\%, 5 wt.\%, 7.5 wt.\%, and 10 wt.\%. Their spectro photometric analysis was carried out to determine their micelle diameter. The graphs of the micelle diameter of the blends against the various concentrations of the ethanol were plotted from which the minimum and maximum obtained, were $26.322 \times 10^{-9} \mathrm{~m}$ and $28.312 \times 10^{-9} \mathrm{~m}$ corresponding to $2.5 \mathrm{wt} . \%$ and $5 \mathrm{wt} . \%$ ethanol concentrations respectively. The same procedure was also repeated for acetone and the values for the minimum and maximum were $24.31 \times 10$ ${ }^{9} \mathrm{~m}$ and $31.798 \times 10^{-9} \mathrm{~m}$ respectively. These concentrations were blended with $400 \mathrm{~g}$ of the oil and their TBP distillations were carried out. From the data generated, $2.5 \%$ and $5 \%$ ethanol were respectively found to enhance the light ends recovery by $6.133 \%$ and $9.008 \%$ for fractions between $I B P-360^{\circ} \mathrm{C}$ for ethanol and $9.500 \%$ and 11.693 $\%$ for 5\% and $2.5 \%$ acetone concentration. The authors are of the opinion that this work can be adapted to enhance light ends recovery in the atmospheric/vacuum distillation units (ADU/VDU) of the Crude Oil Refineries.
\end{abstract}

Keywords: Crude oil, micelle, polar solvent, light-ends, spectrophotometric analysis, TBP distillation, enhancement

\section{INTRODUCTION}

At global level, crude oil business is mostly centered on light crudes, such as Bonny lights, Escravos lights, Arabian lights, Venezuela lights etc. On the contrary, very little attention is being paid to heavy crudes because of the perception that their light distillate content (gasoline, kerosene and diesel fractions) is very low. Apart from that they are relatively difficult to process. Unfortunately, light crude oil reserve is fast depleting [1].

This is perhaps one of the reasons that in the international market a barrel of light crude is more expensive than that of heavy crude. Heavy crude usually contains significant amount of high molecular weight such as asphaltenes and resins which contribute to its high viscosity and adversely influence its processing condition [2]. Through the study of physicochemical properties of crude oil micelle, a lot of information have been gathered on its internal and external structures. From some sets of information, it can be reasonably argued that crude oil could be reduced to a Crude Dispersion System (CDS), the smallest of it being referred to as colloid-dispersal unit (CDU) or micelle as shown in Figure 1. The cytoplasm layer consists mainly of saturates hydrocarbon that is very rich in lighter-ends (gasoline, kerosene and diesel fractions), while the nucleus is mainly of high molecular aromatic hydrocarbon compounds (resinous and asphalthenic).

In a similar development, Speight in [3] equally observed and suggested that feedstock behavior during refining is better addressed through

* Corresponding author, tel: +234-806-911-1718 
consideration of the molecular make-up of the feedstock (perhaps, by analogy, just as genetic makeup dictates human behavior). A model molecular structure has earlier been suggested by [4], describing crude as a form of colloidal association as in Figure 2.

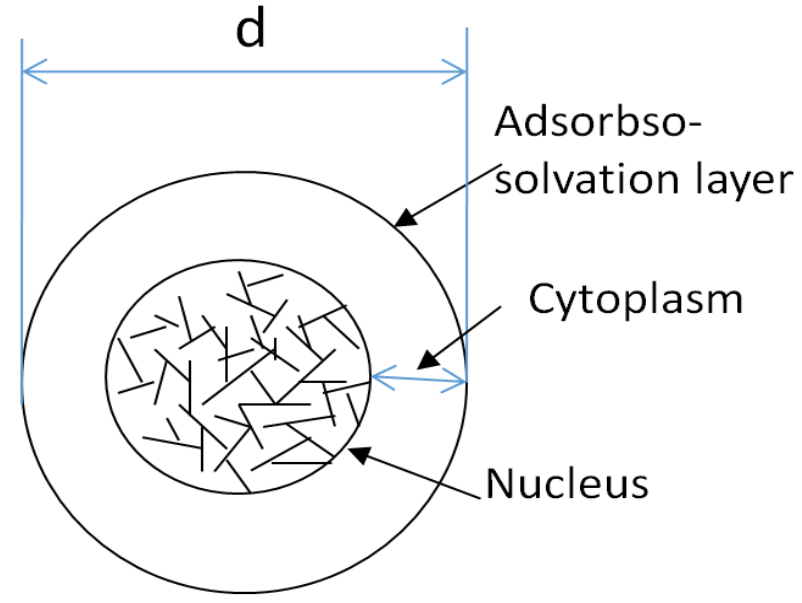

Figure 1: Model of $C D U, d$ is the Average Micelle Diameter

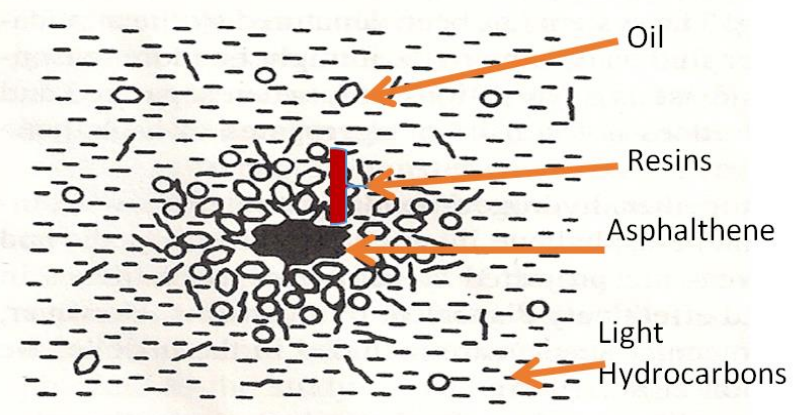

Figure 2: Molecular Structure of Petroleum as a Continuum or Micelle [5]

Though the structures above are over simplified, many scholars in principle believe in its model, theory and existence. Just like quantum atomic theory, there is no rigid interphase between the nucleus and the adsorpso-solvation layer for the various hydrocarbon distribution but rather spreads. The content of each zone can cross from one region to another and this depends on factors and conditions such as temperature, pressure, intermolecular and intramolecular bonding of the hydrocarbon and nonhydrocarbon compounds that constitute the system unit and dispersal agents (solvents)[6]. The best solvent normally employed in dispersing crude oil constituents is n-pentane or n-hexane as in [5]. So in place of any of these, ethanol and acetone could be used. According to [7], this does not justify superiority/inferiority of ethanol and acetone over their nonpolar counterparts like n-pentane or nhexane as dispersing agents, but instead they are capable of solubising polar hydrocarbon compounds in crude oil micelle or crude structural unit (CSU). This behavioral property is irrespective of whether petroleum cum crude oil is heavy or light, or in gaseous, liquid and solid states.

Therefore, the aim of this research work is to study the influence of polar solvents for enhancement of light ends in heavy crude oil distillation unit.

\section{LITERATURE BACKGROUND}

The authors wish to explore the possibility of availing some light components that are suspiciously 'hidden' in the nucleus, hence enhancing the light-ends associated with the crude through the use of polar solvents.

There is the tendency that their introduction into CSU can bring about lesser intermolecular energy, thereby supporting expansion and rearrangements of the constituents of the system [8]. If this is achieved, the particle diameter can be determined using Equation (1) and as well can change to a larger/smaller size (See Molecular profile of $\mathrm{H}_{2}$ in Figure 3). The calculation of the average particle size is gotten from the relationship:

$$
d=\frac{60 \times 10^{5} \mathrm{~kg}}{\rho \times S}
$$

In (1), $d$ is the average particle diameter of crude in $m$ and $\rho$ is the average density of the resin-asphalthenic compounds in $\mathrm{kg} / \mathrm{m}^{3} \mathrm{in}$ the pure crude or the various blends and according to [8], $\mathrm{S}$ is the average specific surface area of the crude or the various blends in $\mathrm{m}^{2}$, which is given as $S=8.08 \times 10^{3} \mathrm{~B}$ and B is coefficient given as:

$$
B=\frac{\log D_{1}-\log D_{2}}{\lambda_{2}-\lambda_{1}}
$$

In (2), $D_{1}$ is the absorbance at wavelength, $\lambda_{1}=620$ $\mathrm{nm}$ and $\mathrm{D}_{2}$ is the absorbance at wavelength, $\lambda_{2}=580$ $\mathrm{nm}$. Using potential energy diagrams, the possible new energy profiles as a result of external influence on crude oil system are shown in Figure 4.For example, in that figure, Molecules type 1 (e.g. crude oil) of the energy level $\mathrm{E}_{11}$ can combine with Molecules types 2 (e.g. polar solvent) of the energy level $\mathrm{E}_{22}$ to form molecule of different energy level $\mathrm{E}_{12}$. Similarly, in the next group of molecular types, Molecules type 1 of energy level $E_{11}$ can combine with Molecules type 2 of energy level $E_{22}$ and Molecules type 3 of energy level $E_{33}$ to form molecule of different energy level of either $E_{23}$ or $E_{12}$ or $E_{13}$ and so on. Within the context of this work, lesser energy level or value supports larger micelle diameter because of low inter molecular force and the resultant effect is ease in separating the molecules during distillation process [8]. 


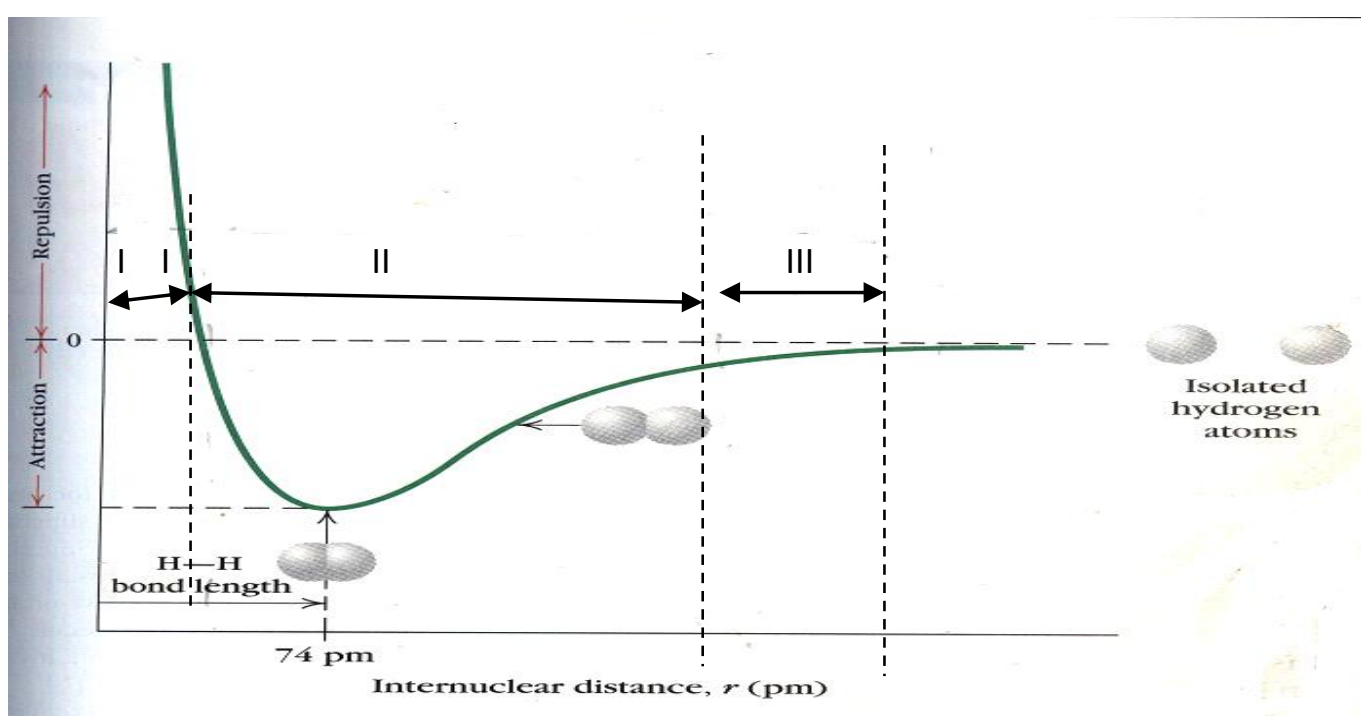

Figure 3: Molecular/energy profile of two hydrogen atoms as a function of their intermolecular distance, $r$.

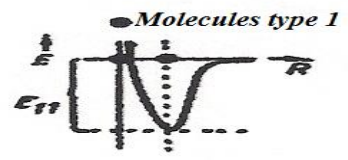

S Molecules type 2

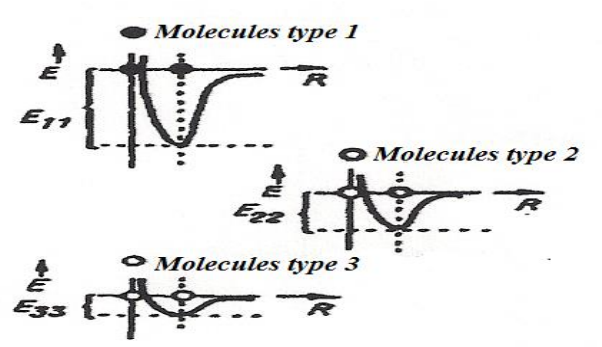

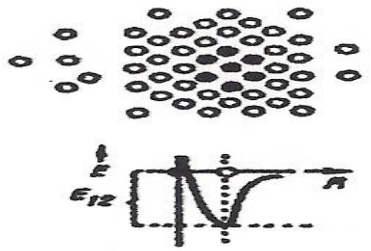
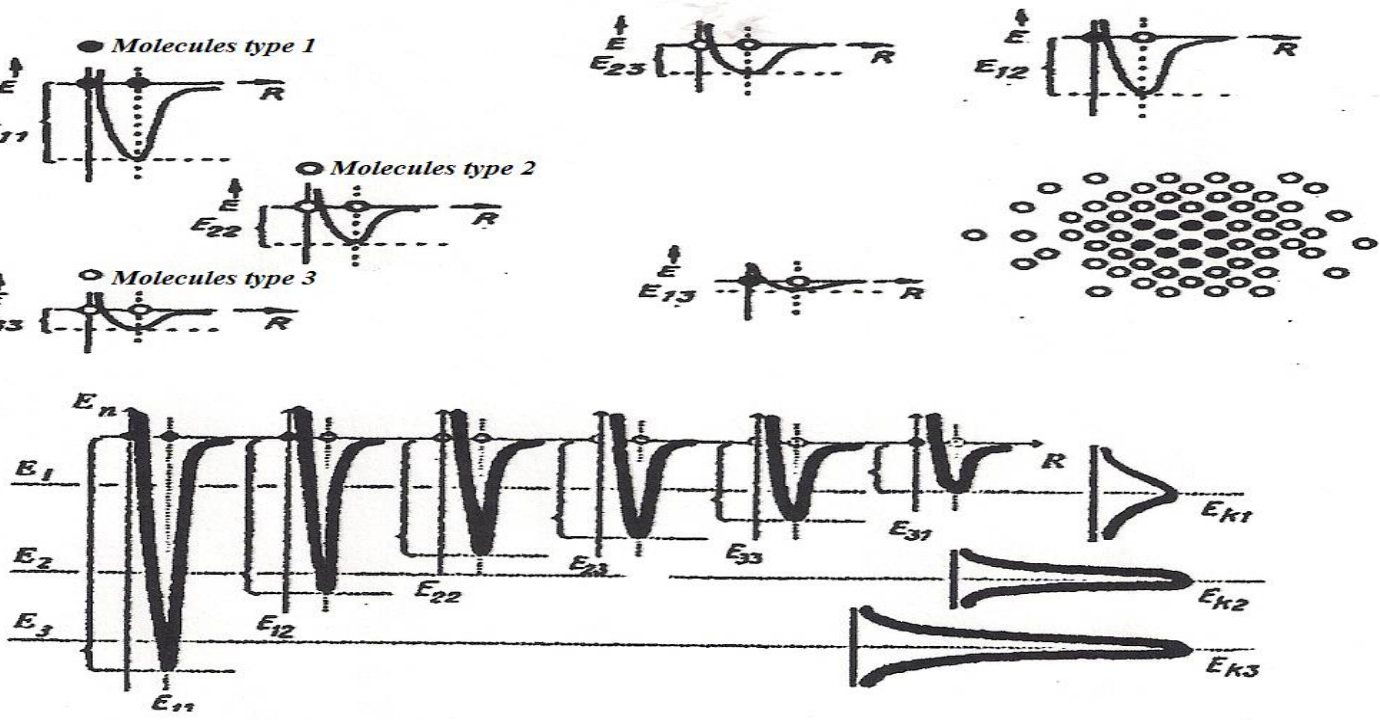

Figure 4: Energy Profile of Intermolecular Relationship of a System

Polar solvents have slight capability of dispersing resino-asphalthenic compounds (RAC), thereby reducing the intermolecular energy and increasing the micelle diameter and enhance the separation of the molecules that constitute crude oil [8] and [9]. In essence, on the average, the larger the diameter of CSU, the higher the light-ends to be expected during a distillation process [10].

\section{EXPERIMENTAL}

As earlier stated, the Venezuela heavy crude sample that was employed in this work was obtained from Kaduna Refining and Petrochemical Company Ltd, Kaduna, Nigeria while the ethanol and acetone of analytical grades were procured from Haddis International Scientific Supplies Co. Nig. Ent. Samaru, Zaria, Nigeria. 
Employing mettler weighing balance of the model and following specifications (Adventurer Pro Model, A1204, Range: 0-200g, Sensitivity: 0.0001g), 8 samples i.e. $2.5 \%, 5 \%, 7.5 \%$ and $10 \% \mathrm{wt} / \mathrm{wt}$ each of ethanol and acetone blends and the virgin crude oil were prepared and allowed to stand for 24 days. Due to the intense dark color of the blends, kerosene was used as blank to dilute them for spectrophotometric analysis. This is quite compatible with the work as reported in [11].

Using JENWAY 6405 UV/Vis spectrophotometer operational procedure, each of the samples was warmed for a period of 20 minutes, charged into the cuvet and then inserted into the test tube well in sample department. The wavelength was selected in wavelength window according to the experimental designation which in this case was 580 and $620 \mathrm{~nm}$ respectively by using wavelength selective knob. Absorbance corresponding to these wavelengths were measured and recorded. The absorbance sets of data that were generated were manipulated for calculating the micelle diameters of virgin and blended crudes. The maximum and minimum diameters were selected as basis for carrying out the True Boiling Point distillation.

Finally, $400 \mathrm{~g}$ of the virgin crude oil was poured into a weighed round bottom flask. The flask was then placed on a magnetic stirrer. Using ASTM D 2864 design specifications and operation procedures as in Figure 5, heat was supplied to the system gradually by the heating mantle of the specification (VDE SS 0721, Electrothermal, 9010 06) after which the first drop of distillate was seen and then recorded as the Initial Boiling Point (IBP). The heating continued gradually until the temperature of the vapor reached $120^{\circ} \mathrm{C}$. The cut between the IBP and $120{ }^{\circ} \mathrm{C}$ was collected in a bottle and weighed. The process heating was allowed to continue and cuts between $120-180{ }^{\circ} \mathrm{C}, 180-240{ }^{\circ} \mathrm{C}$, $240-360{ }^{\circ} \mathrm{C}$ and $360{ }^{\circ} \mathrm{C}+$ were collected and weighed accordingly. This procedure was repeated for $2.5 \%, 5$ $\%, 7.5 \%$ and $10 \%$ ethanol and acetone blends respectively. The TBP distillation setup was assembled using Pyrex quick fits of CORNING Laboratory Division, England

\section{RESULTS}

Our main focus was to generate yields from TBP distillation of virgin and blended Venezuela heavy crude oil with polar solvents (ethanol and acetone) for comparison for higher light-ends recovery. First of all, the spectrophotometric tests as shown in Table 1 of both virgin and the blends were carried out and their absorbance was mathematically manipulated towards determination of the minimum or maximum micelle diameters in Figure 6 . The blends that were responsible for these extreme cases were chosen as basis for carrying out their TBP distillation as presented in Table 2. The light-ends yields were generated for comparison in Tables 3 and 4.

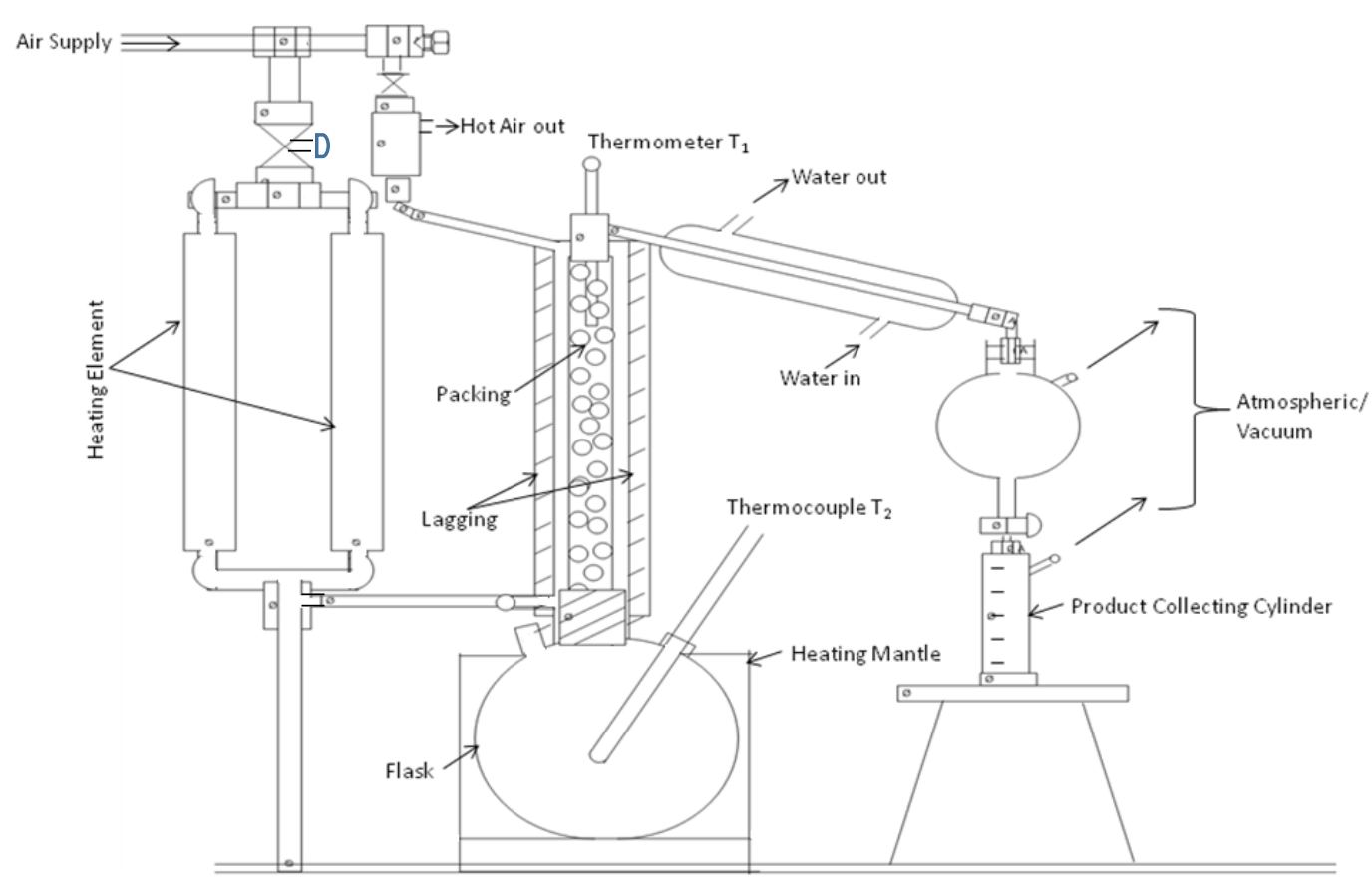

Figure 5: True Boiling Point (TBP) Distillation Apparatus 
Table 1: Spectrophotometric tests and micelle sizes for the heavy crude and ethanol blends

\begin{tabular}{cccc}
\hline \multicolumn{2}{c}{ Absorbance } & Composition & Particle size, $\mathrm{d} \times 10^{-8}(\mathrm{~m})$ \\
\hline $\mathrm{A}_{1}$ at $\lambda_{1}=580 \mathrm{~nm}$ & $\mathrm{~A}_{2}$ at $\lambda_{2}=620 \mathrm{~nm}$ & \%Ethanol & 23.14 \\
1.135 & 0.839 & 0 & 26.32 \\
1.543 & 1.183 & 2.5 & 28.31 \\
1.654 & 1.292 & 5 & 27.17 \\
1.613 & 1.247 & 7.5 & 27.14 \\
1.598 & 1.235 & 10 & \\
\hline
\end{tabular}

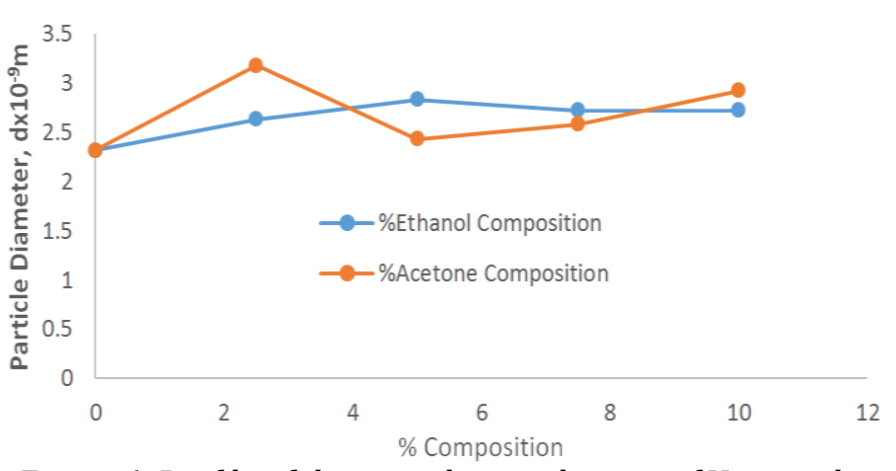

Figure 6: Profile of the particle size changes of Venezuela heavy crude by blending it with ethanol and acetone respectively

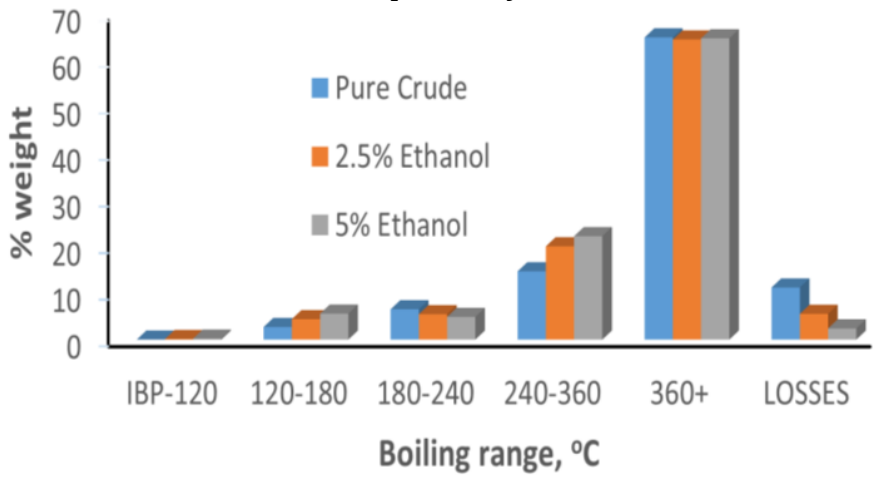

Figure 8: Percentage yields of the fractional cuts for pure crude, $2.5 \%$ and $5 \%$ ethanol blends

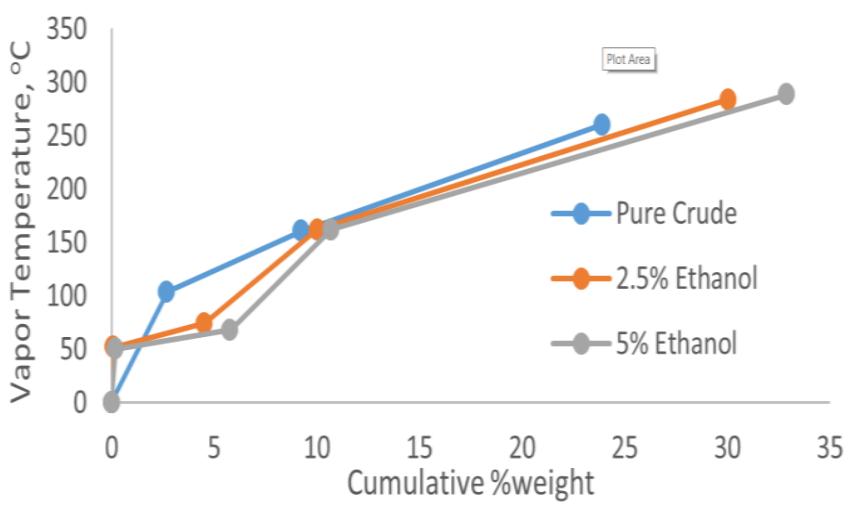

Figure 7: Effect of temperature on cumulative weight for pure crude, $2.5 \%$ ethanol and $5 \%$ ethanol

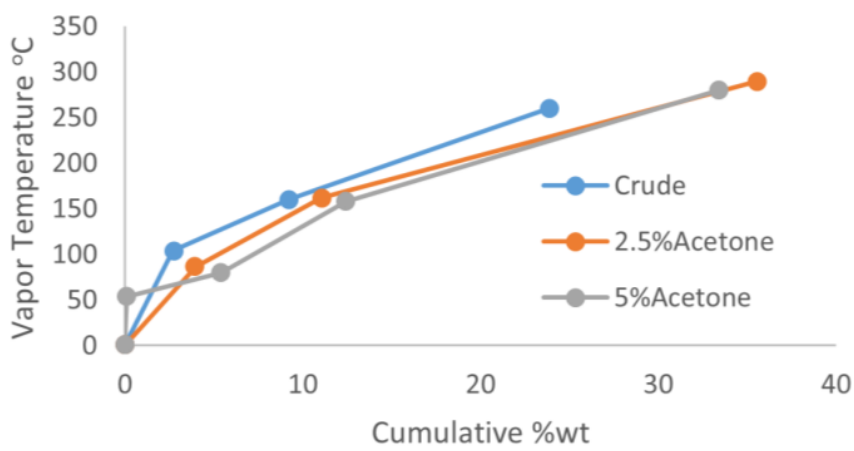

Figure 9: Effect of temperature on cumulative weight for pure crude, $2.5 \%$ ethanol and $5 \%$ ethanol

Table 2: TBP distillation products distribution of the pure crude oil

\begin{tabular}{ccccc}
\hline Boiling Range $\left({ }^{\circ} \mathrm{C}\right)$ & Weight of Cuts $(\mathrm{g})$ & $\%$ wt. & Cumulative \%wt. & Vapor Temperature $\left({ }^{\circ} \mathrm{C}\right)$ \\
\hline IBP-120 & & & & 104 \\
$120-180$ & 10.880 & 2.720 & 2.720 & 160 \\
$180-240$ & 26.080 & 6.520 & 9.240 & 260 \\
$240-360$ & 58.660 & 14.665 & 23.905 & 88.788 \\
360+ & 259.530 & 64.883 & 100 & \\
LOSSES & 44.848 & 11.212 & & \\
\hline TOTAL & 400 & 100 &
\end{tabular}

Table 3: Comparison of the yields of fractional cuts obtained by TBP distillation crude and the various Ethanol blends

\begin{tabular}{cccccc}
\hline \multirow{2}{*}{ Fractional cut, ${ }^{\circ} \mathrm{C}$} & \multirow{2}{*}{ Pure crude 0\% } & \multicolumn{4}{c}{ Change in yields, \% } \\
\cline { 3 - 6 } & & $2.5 \%$ Ethanol & $+/-$ & $5 \%$ Ethanol \\
\hline IBP-120 & 0 & 0.120 & +0.120 & 0.215 & +0.215 \\
$120-180$ & 2.720 & 4.415 & +1.695 & 5.590 & +2.87 \\
$180-240$ & 6.520 & 5.473 & -1.047 & 4.888 & -1.632 \\
$240-360$ & 14.665 & 20.030 & +5.365 & 22.220 & +7.555 \\
Sub-total & 23.905 & 30.038 & +6.133 & 32.913 & +9.008 \\
$360+$ & 64.886 & 64.425 & -0.461 & 64.678 & -0.206 \\
Loss & 11.212 & 5.538 & -5.674 & 2.410 & -8.802 \\
\hline Sub-total & 76.098 & 69.963 & -6.135 & 67.088 & -9.008 \\
\hline Grand-total & 100.000 & 100.000 & 0.000 & 100.000 & 0.000 \\
\hline
\end{tabular}


Table 4: Comparison of the yields of fractional cuts obtained by TBP distillation of the crude and the various acetone blends

\begin{tabular}{cccccc}
\hline \multirow{2}{*}{ Fractional cut, ${ }^{0} \mathrm{C}$} & Pure crude & \multicolumn{4}{c}{ Change in yields, \% } \\
\cline { 3 - 6 } & $0 \%$ & $2.5 \%$ Acetone & $+/-$ & $5 \%$ Acetone & $+/-$ \\
\hline IBP-120 & 0 & 0 & 0 & 0.105 & +0.105 \\
$120-180$ & 2.720 & 3.985 & +1.265 & 5.288 & +2.568 \\
$180-240$ & 6.520 & 7.085 & +0.565 & 7.063 & +0.546 \\
$240-360$ & 14.665 & 24.525 & +9.863 & 20.925 & +6.264 \\
Sub-total & 23.905 & 35.595 & +11.693 & 33.381 & +9.500 \\
$360+$ & 64.886 & 58.510 & -6.376 & 63.280 & -1.606 \\
Loss & 11.212 & 5.895 & -5.317 & 3.318 & -7.894 \\
\hline Sub-total & 76.098 & 64.405 & -11.693 & 66.598 & -9.500 \\
\hline Grand-total & 100.000 & 100.000 & 0.000 & 100.000 & 0.000 \\
\hline
\end{tabular}

\subsection{Particle Size Determination}

Similarly, the spectrophotometric tests and particle size determination for the heavy crude and acetone blends were carried out and the data generated are shown in Table 5 in Appendix A. Profile of the particle size changes as function of the virgin and percentage blends is hereby displayed in Figure 6.

\subsection{True boiling point (TBP) distillation determination}

Similarly, TBP distillation products distribution of the pure crude oil and $2.5 \%$ and $5 \%$ ethanol blends were generated as Tables 6 and 7 and they are carried to Appendix B. TBP distillation was equally carried out for $2.5 \%$ and $5 \%$ acetone blends and the comparison of the percentage yields of the pure crude and these blends is represented in Figure 9 and Table 3.

Basis: $400 \mathrm{~g}$ of heavy crude oil

Pure crude with no solvent $=400 \mathrm{~g}$

$2.5 \%$ Ethanol + Pure crude oil $=10 \mathrm{~g}+390 \mathrm{~g}=400 \mathrm{~g}$

$5.0 \%$ Ethanol + Pure crude oil $=20 \mathrm{~g}+380 \mathrm{~g}=400 \mathrm{~g}$

$2.5 \%$ Acetone + Pure crude oil $=10 \mathrm{~g}+390 \mathrm{~g}=400 \mathrm{~g}$

$5.0 \%$ Acetone + Pure crude oil $=20 \mathrm{~g}+380 \mathrm{~g}=400 \mathrm{~g}$

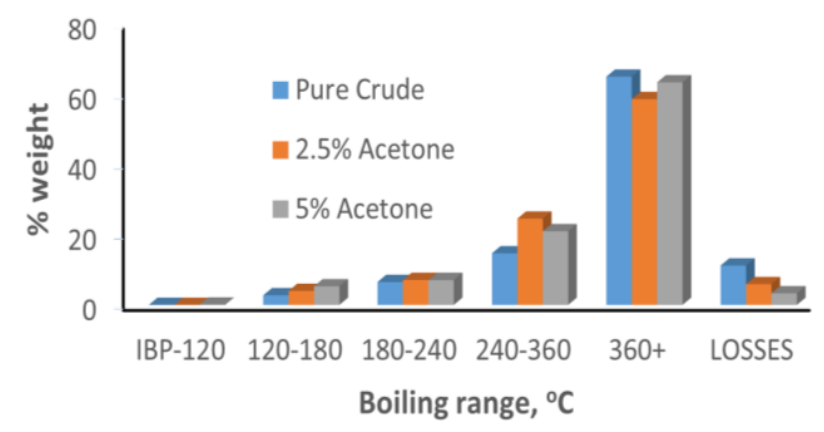

Figure 10: Percentage yields of the fractional cuts for pure crude, $2.5 \%$ and $5 \%$ acetone blends

\section{DISCUSSION OF RESULTS}

As can be observed in the spectrophotometric analysis in Table 1of the pure crude and the blends, there is no defined pattern of changes in the particle sizes as shown in Figure 6. This is quite in agreement with what [7] and [11] reported in their works, whereby spent engine oil was employed as blend to carry out enhancement of the light ends of their heavy crudes that were investigated. However, their works and Figure 6 guided the Authors on the selection or choice of the particle size that would likely enhance the light ends during a distillation exercise. In essence, this work did not establish that the larger the particle size, the higher the extent of enhancement of the light ends which is contrary to what [12] reported. Of course, the minimum and maximum obtained, were $26.322 \times 10^{-9}$ $\mathrm{m}$ and $28.312 \times 10^{-9} \mathrm{~m}$ corresponding to $2.5 \mathrm{wt} . \%$ and $5 \mathrm{wt} . \%$ ethanol concentrations respectively and the minimum and maximum obtained were $24.31 \times 10^{-9} \mathrm{~m}$ and $31.798 \times 10^{-9} \mathrm{~m}$ corresponding to $5 \mathrm{wt} . \%$ and 2.5 wt.\% acetone concentrations respectively. Thus, the minimum concentration in ethanol corresponds to the maximum for acetone and the vice versa. Extending this kind of research outcome to large scale situation (atmospheric/vacuum distillation in the refineries), spectrophotometric analysis for selection of particle size have only served the purpose of guidance [1]. Also, shown in Figures 8 and 9 are the percentage yields of the fractional cuts for the pure crude, the ethanol and acetone blends. As it can be observed that there were light ends enhancement across all the fractional cuts for acetone blends, but on the other hand, the ethanol blend did not show the same behavior. In this regard, Saidakhmedov in [13] stated that the main goal of using external influences (e.g., thermolysis, photolysis, acoustic sound, additives, etc.) for enhancement of light ends is to maximize their fractional cuts which may be as high as $5-7 \%$ and not the pattern of distribution of product slate. In this work the Authors believe that this has been achieved because $2.5 \%$ and $5 \%$ ethanol was respectively found to enhance the light ends recovery 
by $6.133 \%$ and $9.008 \%$ for fractions between IBP-360 ${ }^{\circ} \mathrm{C}$ for ethanol and $9.500 \%$ and $11.693 \%$ for $5 \%$ and $2.5 \%$ acetone concentration respectively.

Across Tables 3 and 4 was encountered mostly positive and few negative enhancement values of the fractional cuts. This should not be too strange, because the products enhancement is not entirely a physical phenomenon, but as well related to a thermal decomposition [14] and [15] whose mechanisms is beyond the scope of this work.[16], [17] and [18]also reported asphaltenes decomposition process in heavy crude oils and according to them this unavoidable thermal reaction can result into the formation of lighter ends and coke products. Of importance too, to mention is the fact that the thermal reaction mechanisms are difficult to establish [5] and as such underscores the reasons that any definite trend on their contribution to light ends recovery cannot be predicted.

It must also be stated that some losses of the products were reported across all the Tables 3 and 4 . It was revealed according to [19] that these losses are partially related to light hydrocarbon gases that could not be trapped within the limit of construction of most TBP distillation apparatus and some due to leakages from joints.

\section{CONCLUSIONS}

Within the limits of experimental error(s), the following conclusions can be made:

Enhancement of the light-ends as a result of blending heavy crude oil with solvents through distillation process was achieved.2.5\% and $5 \%$ ethanol was respectively found to enhance the light ends recovery by $6.133 \%$ and $9.008 \%$ for fractions between IBP-360 ${ }^{\circ} \mathrm{C}$ for ethanol and $9.500 \%$ and $11.693 \%$ for $5 \%$ and $2.5 \%$ acetone concentration. Most of the reported cases of enhancement of light ends by using the same method were in the range of $2-7 \%$ by weight on the crude.

It must also be stated that the influence of micelle diameters of the pure and blended crudes on the outcome of the light ends cannot be overemphasized. For the blended Venezuela heavy crude, the minimum and maximum obtained, were $26.322 \times 10^{-9} \mathrm{~m}$ and $28.312 \times 10^{-9} \mathrm{~m}$ corresponding to $2.5 \mathrm{wt} . \%$ and $5 \mathrm{wt} . \%$ ethanol concentrations respectively while the values for the minimum and maximum were $24.31 \times 10^{-9} \mathrm{~m}$ and $31.798 \times 10^{-9} \mathrm{~m}$ respectively.

Finally, influence of particle size of the blends cannot be used to predict the pattern of distribution of the product slate. It would have been expected that after conducting the spectrophotometric analyses of the blends, that should have been enough to establish across, the overall increment or decrement of the whole product slates. Unfortunately, this is not so. It is still expected that TBP distillation analysis must be carried out for final outcome of product distribution. This can be laborious and time consuming and thereby making the whole idea of the work less justifying.

\section{REFERENCES}

[1] Momoh O. R., Ahmed A. S., Mohammed-Dabo I. A. and Ajinomh C. S.; Enhancing Light-ends Recovery by True Boiling Distillation of Heavy Crude Oil and Used Engine Oil Blend. Nigerian Journal of Engineering, 18(1), 120-125. Sept. (2011).

[2] John, S. N., "Investigating the Effect of Used Engine Oil on the Atmospheric Distillation of Antan Heavy Crude", Unpublished Research Project Submitted to Department of Chemical Engineering, Ahmadu Bello University, Zaria. (2008).

[3] Speight, J. G. In Asphaltenes and Asphalts. International Developments in Petroleum Science, 40. T.F. Yen and G. V. Chilingarian (Editors), Elsevier, Amsterdam, The Netherlands. Chapter 2. (1994).

[4] Pfeiffer, J.P. and Saal, R. N, Asphaltic Bitumen as Colloid System. Journal of Phys. Chem. 44 (2), 139149, 1940.

[5] Speight, J. G. The structure of petroleum. In: Chemical Industries (Ed). The Chemistry and Technology of Petroleum. 3rd edition, Revised and Expanded; Marcel Dekker, Inc., New York. Basel, pp. 475-481, 1999.

[6] Safieva R. Z. Physicochemistry of Crude Oil, Physicochemical Basis of Refining Crude Oil. M.: Chemistry, Moscow, pp 1-448. (1998).

[7] Unger F. G. and Andreeva L. N., Fundamental Aspects of the Oil Chemistry, Nature of the Resins and Asphalthenes, Novosibirsk Nauka, Siberian Publishing Firm. (1995);

[8] Mohammed I. A., Composition, Structure and Properties of Petroleum as feed for atmospheric and vacuum distillation; Unpublished Ph.D. Dissertation; Moscow. (2001);

[9] K. W. and Teh F. Y.; An Electron Spin Resonance Probe Method for the Understanding of Petroleum Asphaltene Macrostructure. Journal of Petroleum Science and Engineering ${ }_{2}$ Vol. 28, pp. 55-64, 2000.

[10] Sunyaev Z. I., Sunyaev R. Z. and Safieva R. Z. Petroleum Dispersion system, Chemistry Moscow, Russia. (1990). 
[11] Momoh, O.R., “Enhancing Light Ends Recovery through Joint Atmospheric Distillation of Heavy Crude and Used Engine Oil". Published Ph.D Dissertation Submitted to Department of Chemical Engineering, Ahmadu Bello University, Zaria. (2011).

[12] Ajibogun, Y., "Enhancing the Recovery of Light Ends of Escravos Heavy Crude by its Joint Atmospheric Distillation with Used Engine Oil". Unpublished Research Project Submitted To Department of Chemical Engineering, Ahmadu Bello University, Zaria. (2009).

[13] Saidakhmedov I. M., Glagoleva O. F. and Grushevenko A. E. Increasing the Distillate Yields in Atmospheric Distillation of Crude Oil by Means of Activating Additives. Translated from the Book: Khimiya I Tekhnologiya Topliv i Masel, No. 1, Moscow, Russia, pp.8-9. (1986).

[14] Ajinomoh, C. S. Physico-chemical methods of activating heavy crude oil feedstock components. Unpublished Ph.D. Dissertation. Moscow Pure
Chemical Engineering Academy, Moscow, Russia. (2005).

[15] Quirke J. M. E. Metal Complexes in Fossil Fuels. R.H. Filby and J.F. Branthaver (Editors). Symposium Series, No. 344. American Chemical Society, Washigton D C, p.74. (1987).

[16] Bjorseth, A. Handbook of Polycyclic Aromatic Hydrocarbons, Mercel Dekker Inc., New York, USA. (1983).

[17] Dias J.R. Handbook of Polycyclic Aromatic Hydrocarbons, Part A. Benzoid Hydrocarbons. Elsevier, New York, USA. (1987).

[18] Dias J. R. Handbook of Polycyclic Aromatic Hydrocarbons, Part B. Polycyclic Isomers and Heteroatom Analogs of Benzoid Hydrocarbons. Elsevier, New York, USA. (1988).

[19] Erikh V. N., Rasina M. G. and Rudin M. G. The Chemistry and Technology of Petroleum and Gas. Mir Publishers; Moscow, pp. 22- 48. (1988). 